\title{
Supplement of Compositions and mixing states of aerosol particles by aircraft observations in the Arctic springtime, 2018
}

Kouji Adachi $^{1}$, Naga Oshima ${ }^{1}$, Sho Ohata ${ }^{2,3,4}$, Atsushi Yoshida ${ }^{2}$, Nobuhiro Moteki ${ }^{2}$, and Makoto Koike ${ }^{2}$

$5{ }^{1}$ Department of Atmosphere, Ocean, and Earth System Modeling Research, Meteorological Research Institute, Tsukuba, Japan

${ }^{2}$ Department of Earth and Planetary Science, Graduate School of Science, The University of Tokyo, Tokyo, Japan

${ }^{3}$ Institute for Space-Earth Environmental Research, Nagoya University, Nagoya, Japan

$10{ }^{4}$ Institute for Advanced Research, Nagoya University, Nagoya, Japan

Correspondence to: Kouji Adachi (adachik@mri-jma.go.jp)

Figures S1 to S11.

15 Table S1. 


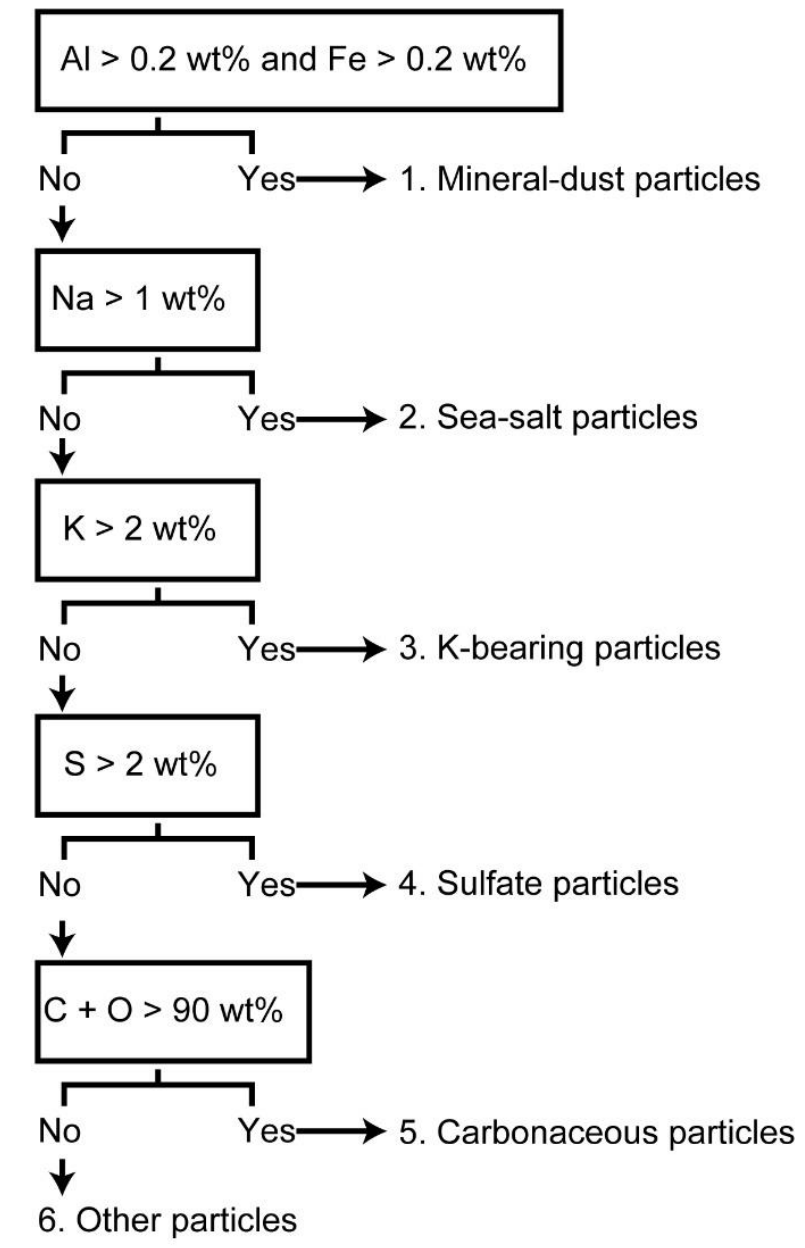

Figure S1. Flow chart to classify the individual particles into six categories based on the STEM-EDS 20 measurements. This flow chart is nearly the same as that in Adachi et al. (2020), but we excluded primary biological aerosol particles (P-bearing particles) in the current study. 


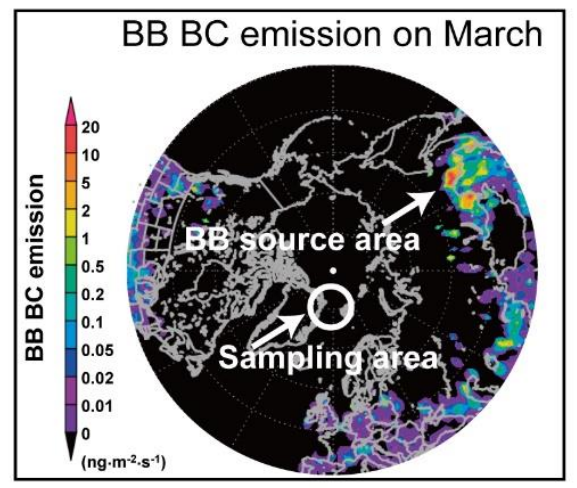

1) $12: 00$, March $28(950 \mathrm{hPa})$

2) 12:00, March $29(950 \mathrm{hPa})$

3) 12:00, March $30(800 \mathrm{hPa})$
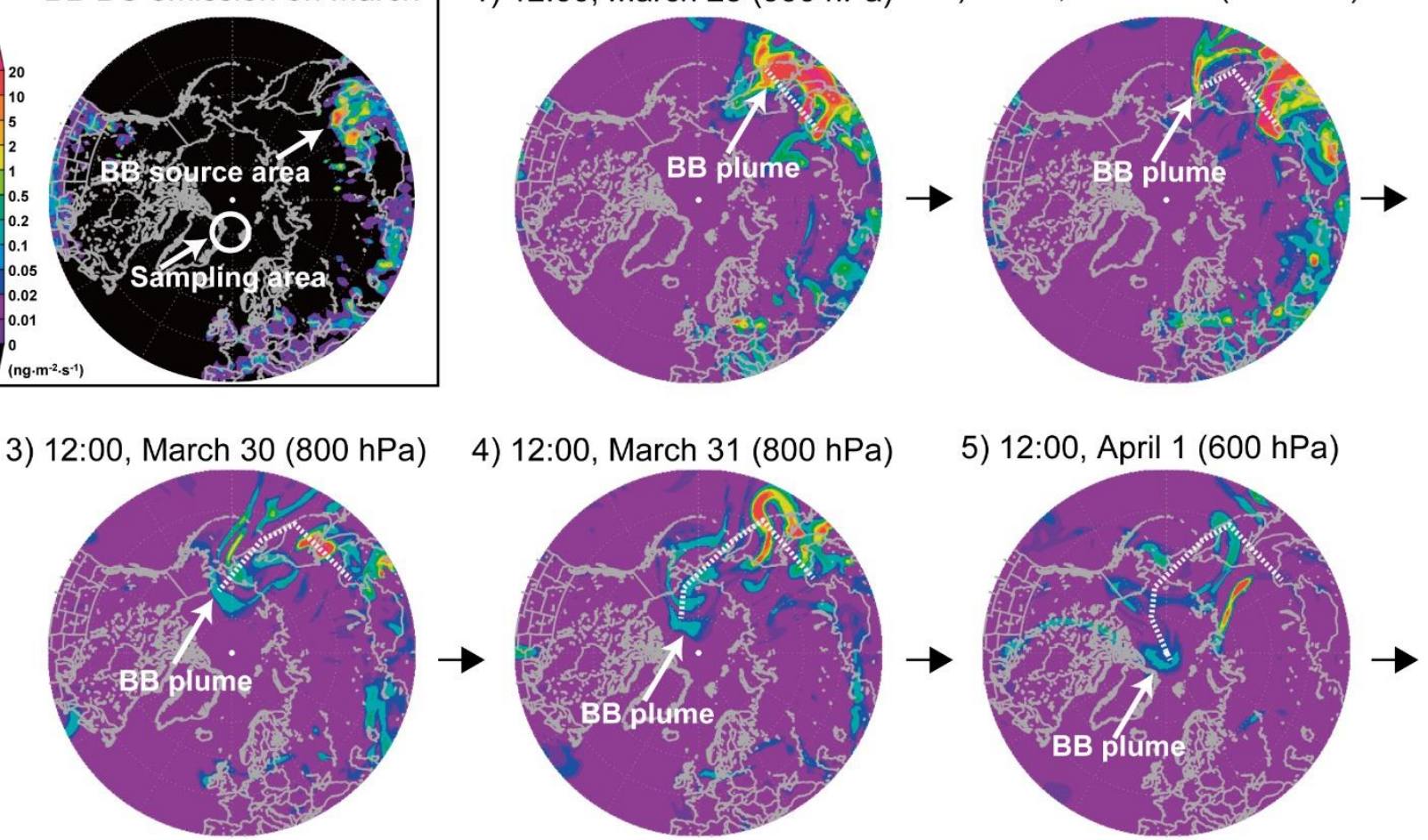

4) 12:00, March $31(800 \mathrm{hPa})$

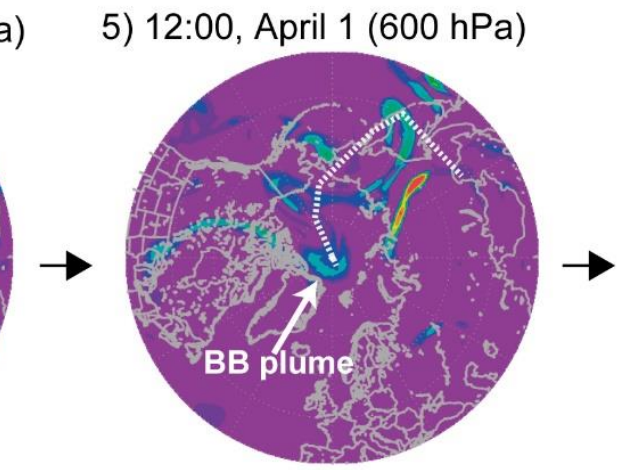

6) 12:00, April $2(600 \mathrm{hPa})$
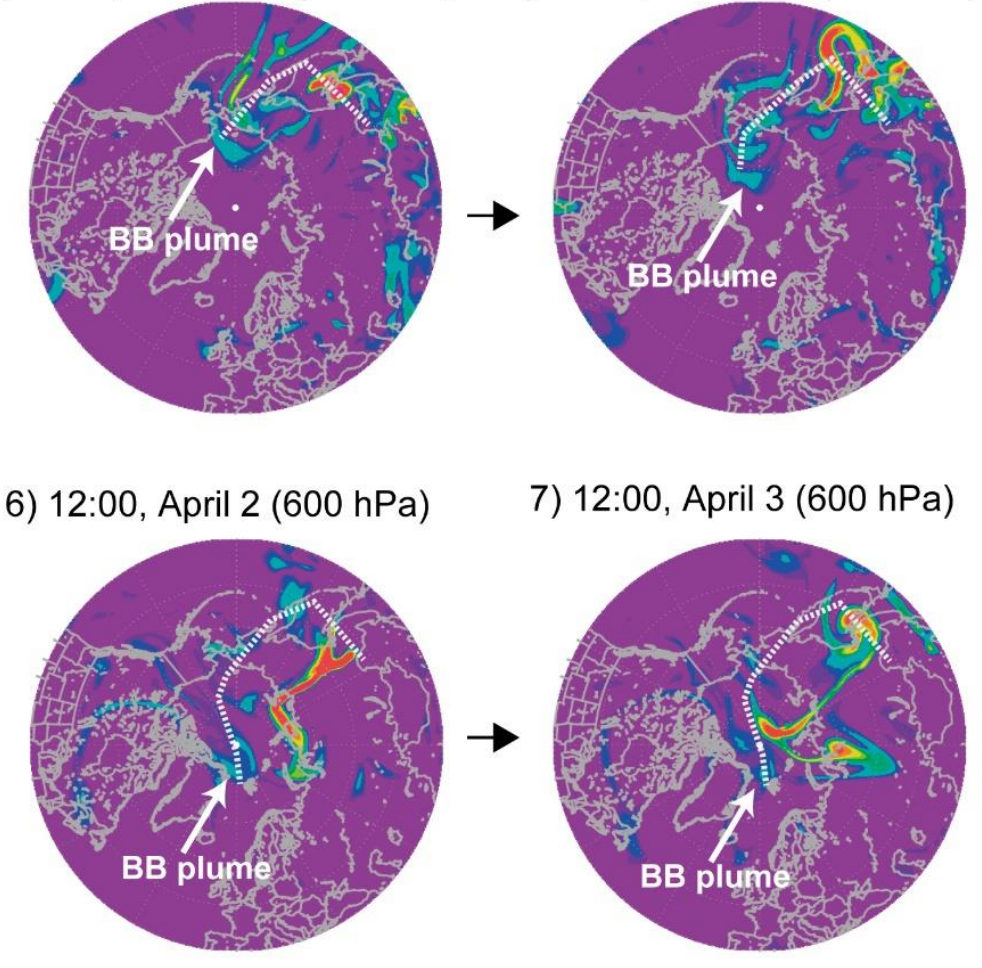

7) 12:00, April $3(600 \mathrm{hPa})$

8) 12:00, April $4(600 \mathrm{hPa})$
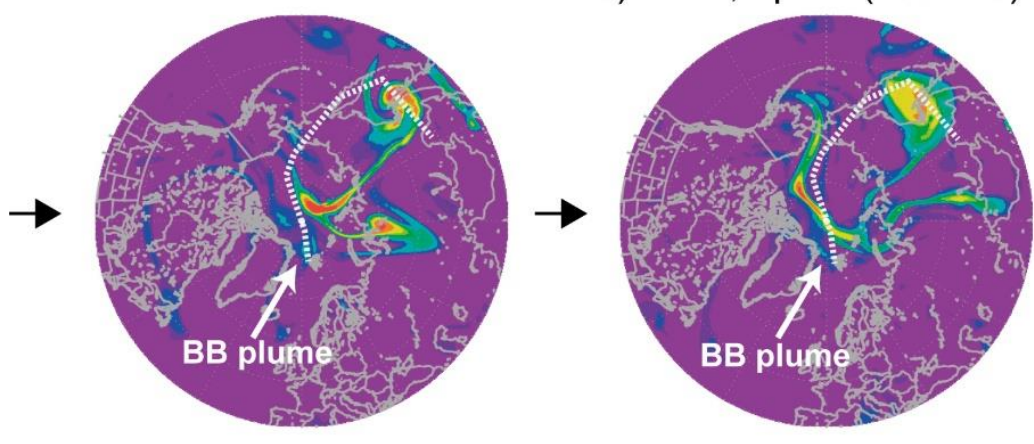

BB BC mass concentration

$5 \quad 10 \quad 20 \quad 40 \quad 60 \quad 80100150200500\left(\mathrm{ng} / \mathrm{m}^{3}\right)$

Figure S2. Black carbon (BC) emissions from biomass burning (BB) in March 2018 (upper left) and horizontal distributions of the mass concentration of BC originating from BB from 28 March to 4 April 2018 at 12:00 UTC (1-8). The dotted lines indicate the transport pathway of the BB BC plume that reached the sampling area between 2 and 4 April. Note that the pressure (altitude) levels are different in each panel depending on the air mass transport. 
(a)
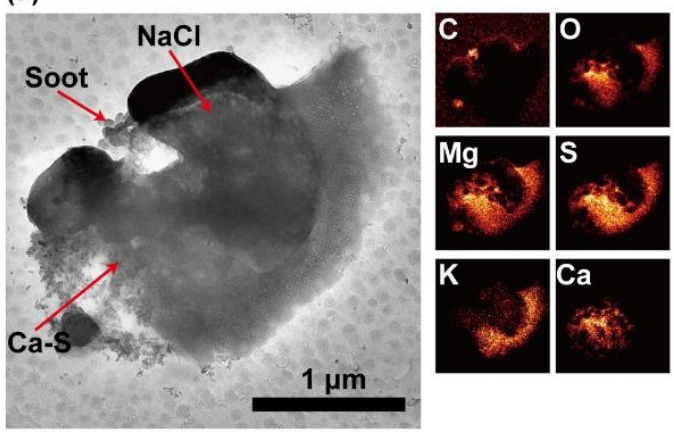

(c)
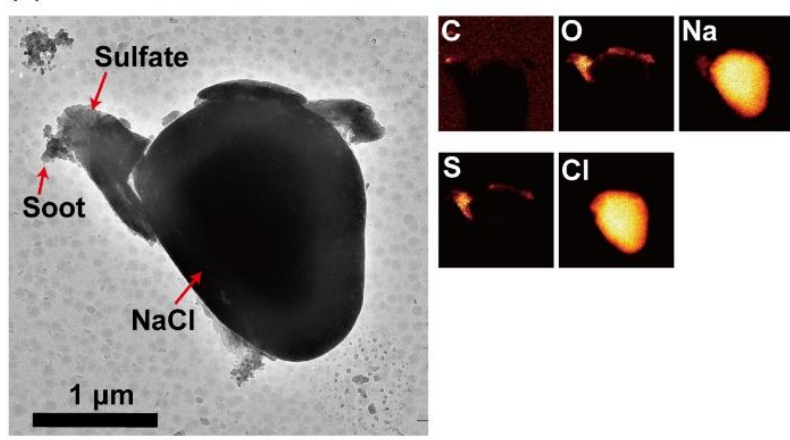

(e)
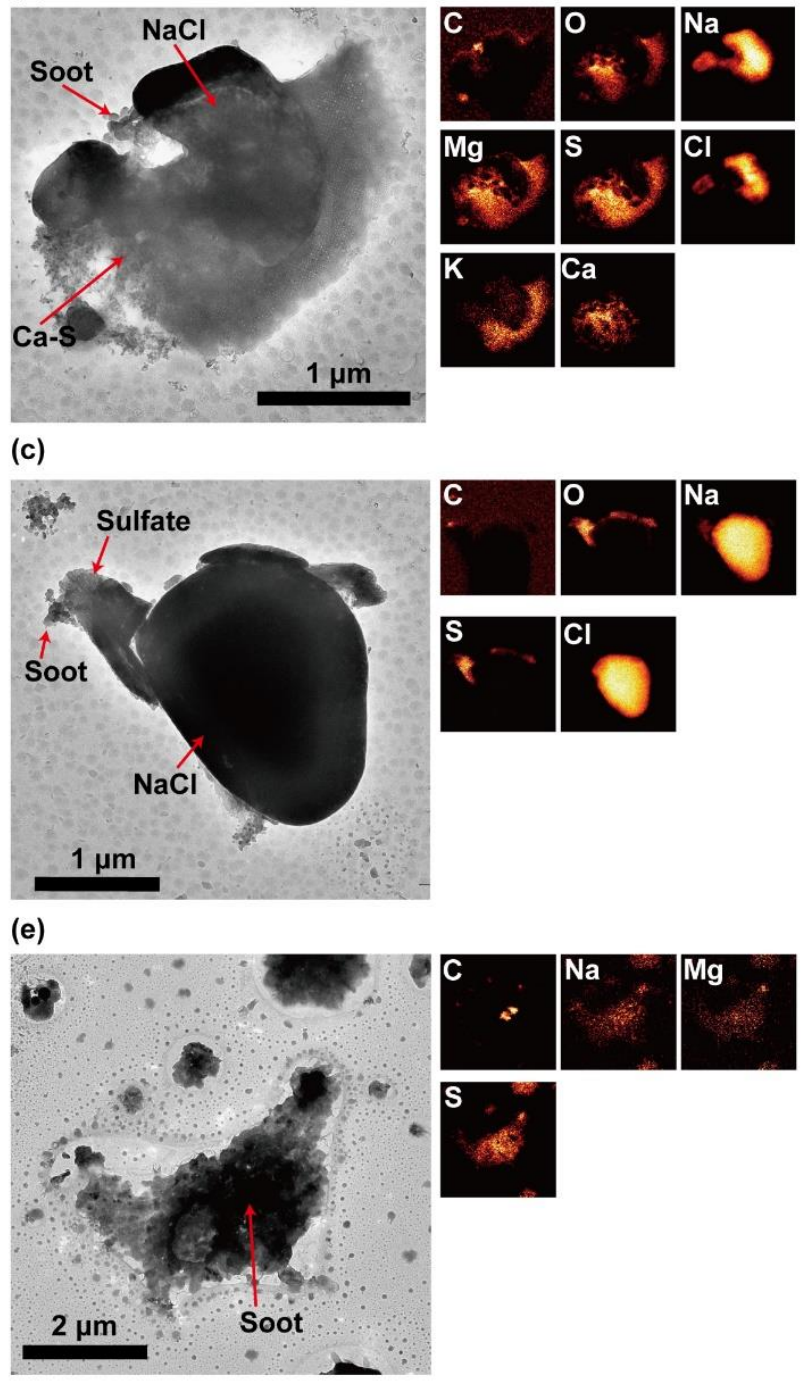

(b)
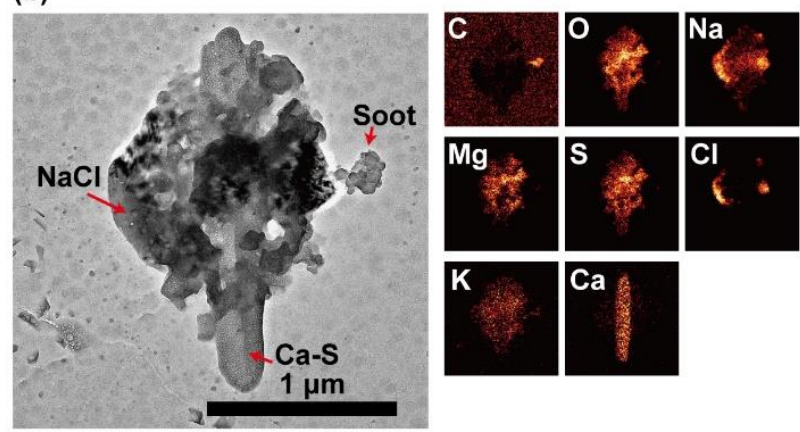

(d)

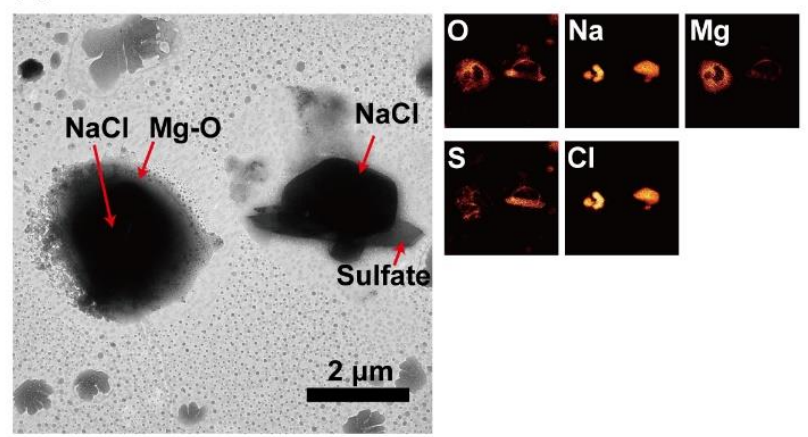

(f)

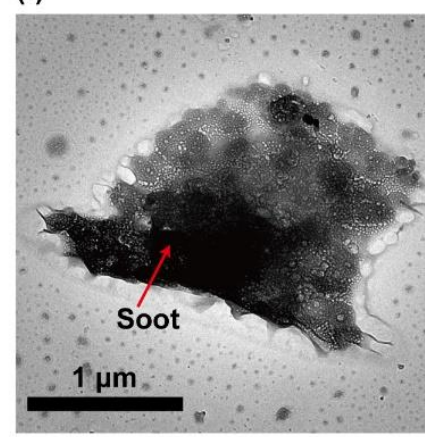

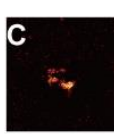

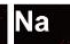

$\mathrm{Mg}$

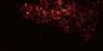

$\mathbf{S}$
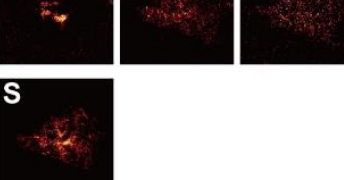

Figure S3. TEM and elemental mapping images of the sea-salt particles. The particles in (a), (b), (c),

and (d) were collected from 10:00-10:19, 30 March, 2018, and those in (e) and (f) were collected from 14:40-14:59, 31 March. The left TEM image in each panel shows the sea-salt particles mixed with various grains. Elemental mapping images of the TEM areas for the detected elements are shown on the right in each panel. Chlorine was not detected in the particles in (e) and (f) because of $\mathrm{Cl}$ replacement with sulfate in the atmosphere. 


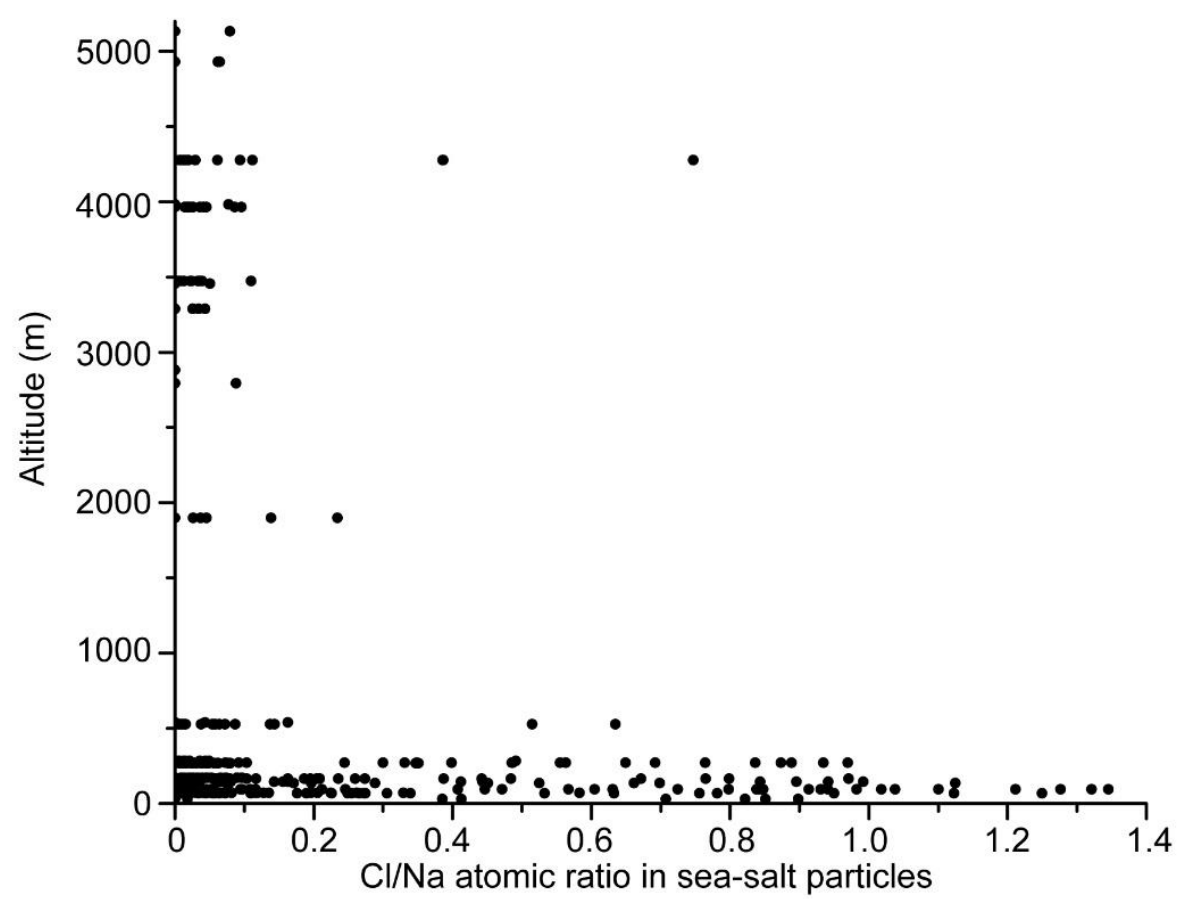

Figure S4. Ratios of $\mathrm{Cl}$ to $\mathrm{Na}$ in the atomic ratio for all individual sea-salt particles. Chlorine was largely lost in the particles collected above $1000 \mathrm{~m}$. 


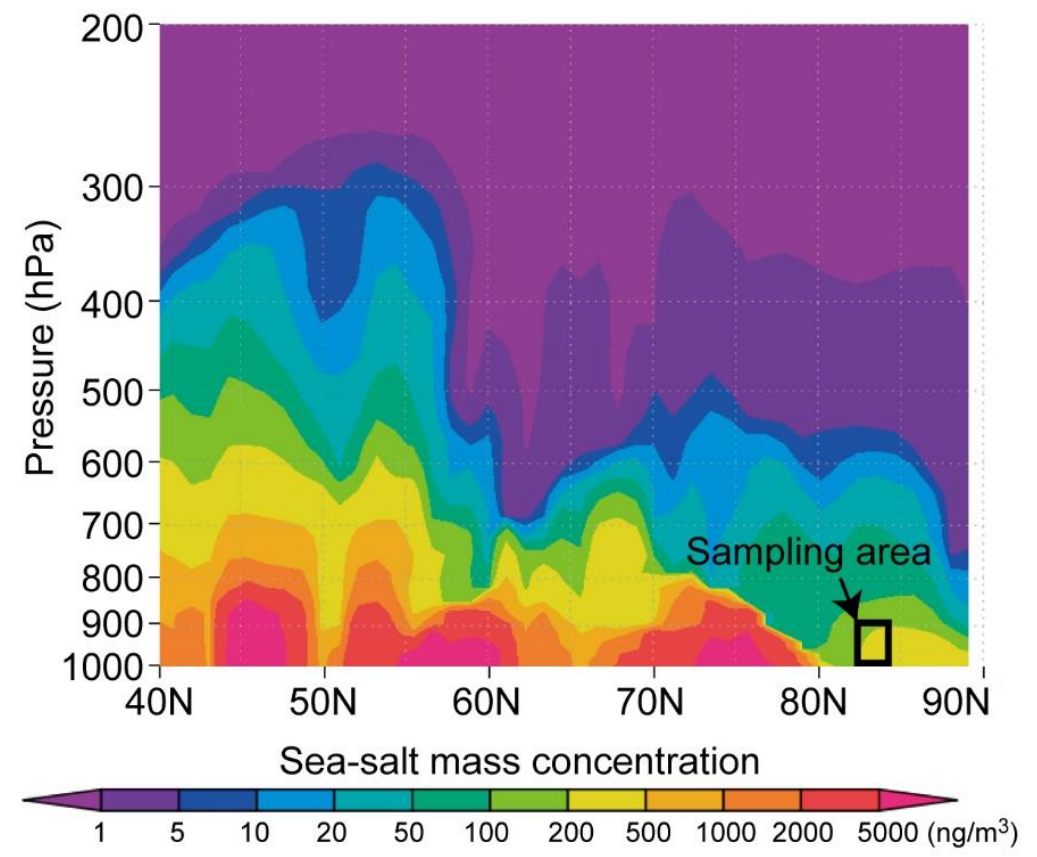

Figure S5. Example model result of the vertical distribution of the sea-salt mass concentration on 12:00

40 UTC, 30 March 2018 at $0^{\circ} \mathrm{E}$ longitude. The sea-salt number fractions in the TEM analysis were relatively high on that day. The sampling area is shown in a black square. 


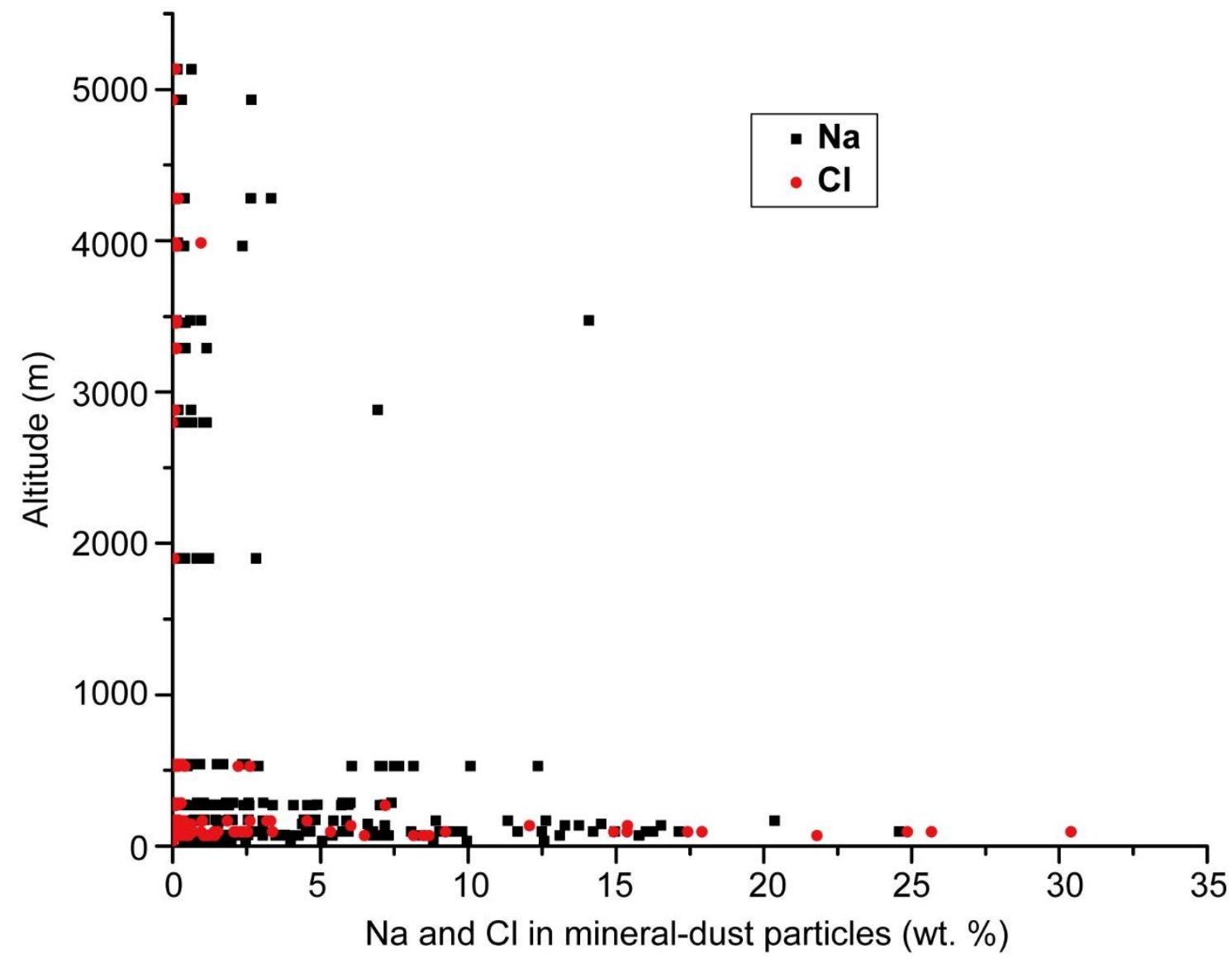

Figure S6. Weight percent of $\mathrm{Na}$ (black) and $\mathrm{Cl}$ (red) within all mineral-dust particles along with their sampling altitude. The sea-salt fractions within the individual mineral-dust particles are high at a low altitude. 
(a) Horizontal dust distribution at $950 \mathrm{hPa}$

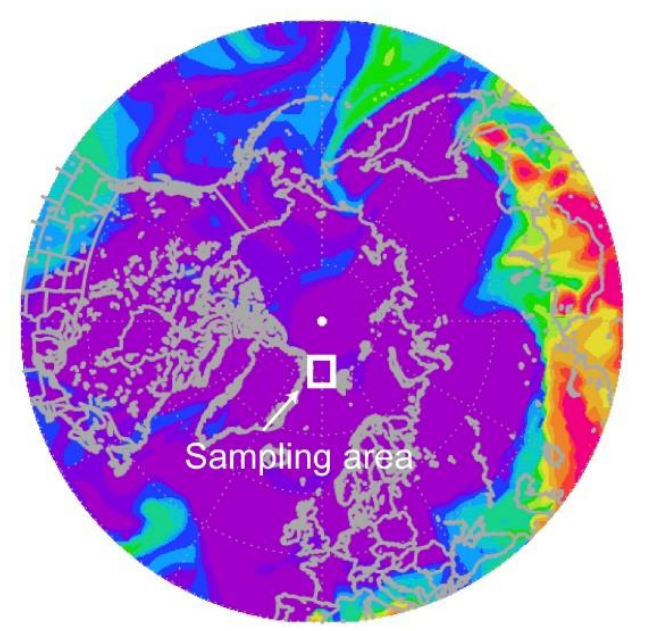

(b) Vertical dust distribution at $10^{\circ} \mathrm{E}$ longitude

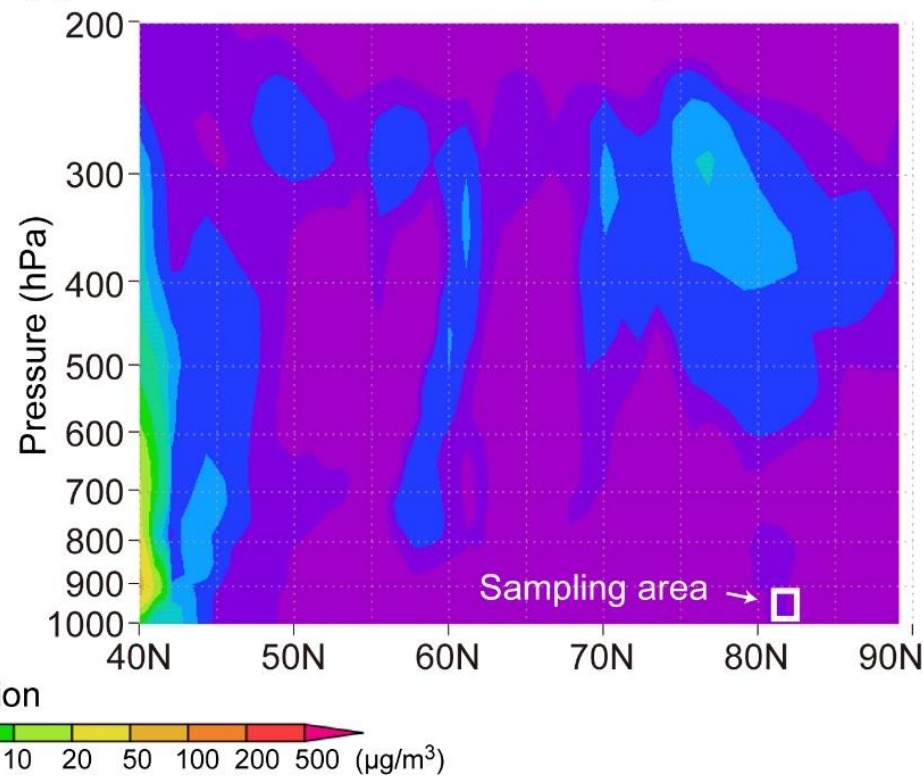

Figure S7. Example model results of the (a) horizontal and (b) vertical distributions of the mineral-dust 50 mass concentration on 12:00 UTC, 30 March 2018. The mineral-dust number fractions in the TEM analysis were relatively high on that day, but no dust plume was detected in the model. The vertical distribution is shown along the $10^{\circ} \mathrm{E}$ longitude. The sampling area is shown in the white squares. 
(a)

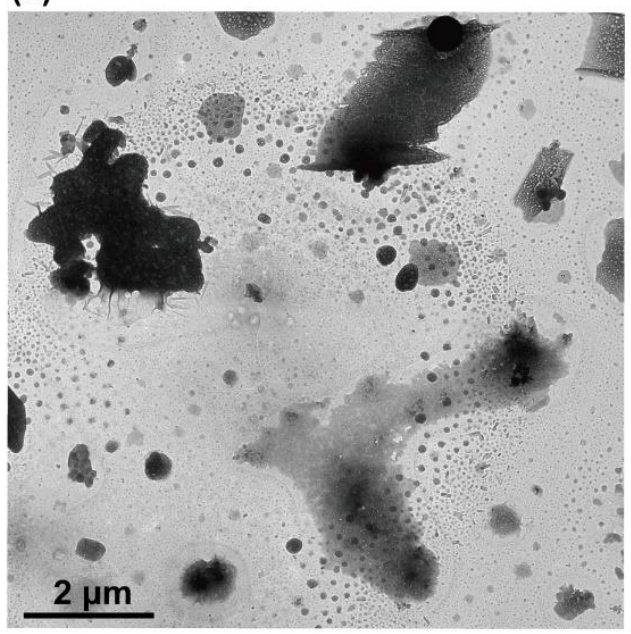

(b)
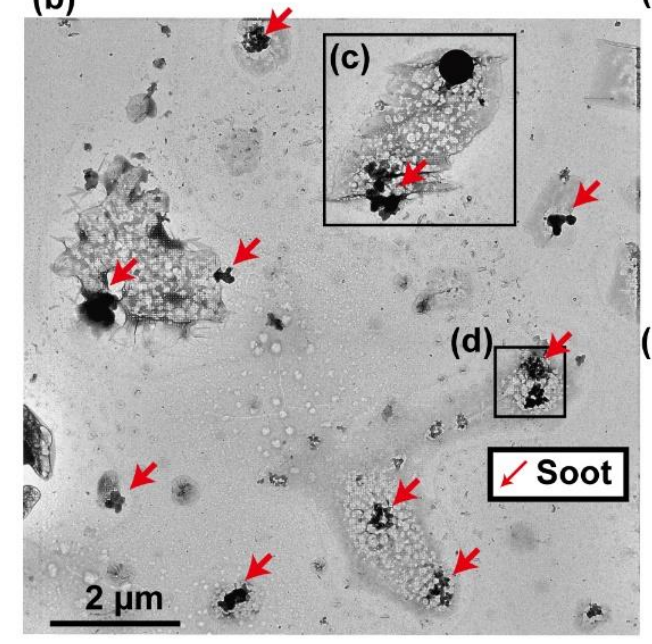

(c)

(d)
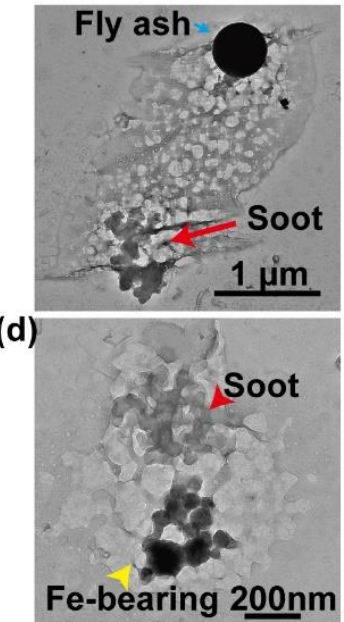

(e)
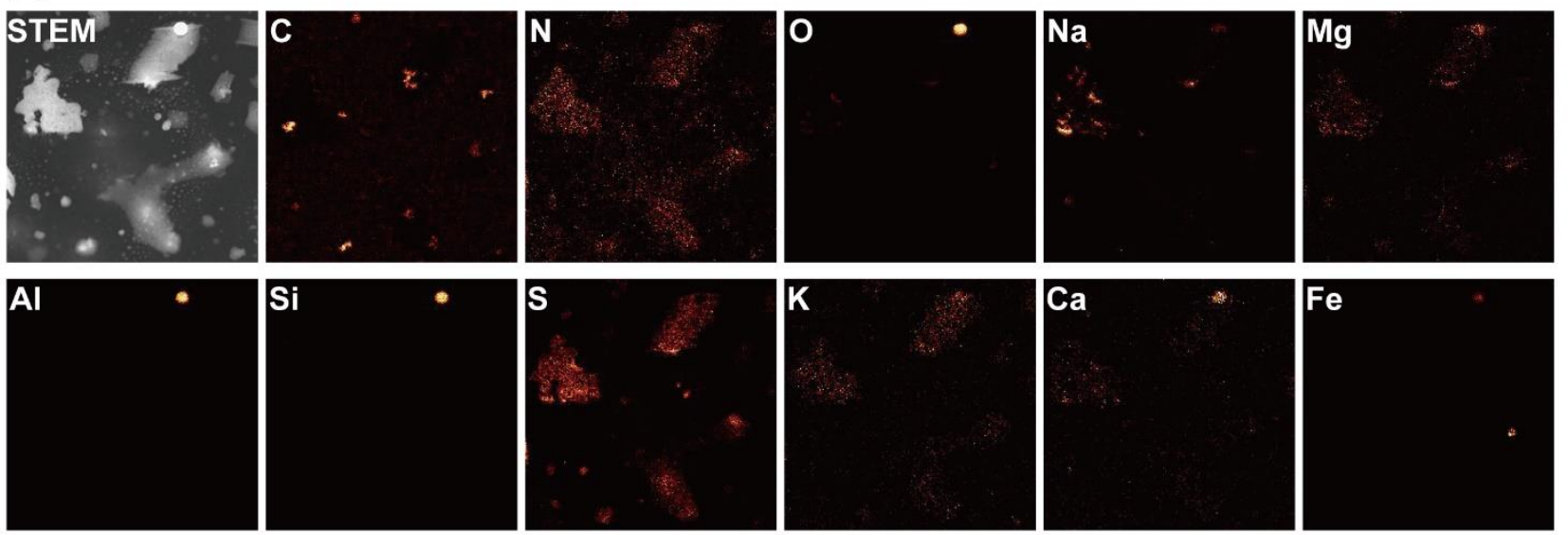

55 Figure S8. TEM and elemental mapping images of the sulfate particles containing inclusions. (a) TEM image before the mapping analysis and (b) after the mapping analysis. Electron-beam exposure removed sulfate, and the inclusions became more apparent. (c) A particle in the image (b) with fly-ash and soot inclusions. (d) A particle with Fe-aggregate and soot inclusions. (e) Elemental mapping images of the TEM areas of the detected elements. The $\mathrm{C}$ distributions in the mapping image correspond to the soot particles. The fly-ash particle in (c) includes $\mathrm{O}, \mathrm{Al}$, and $\mathrm{Si}$ as its main components. Fe is apparent in the Fe-aggregate particle in (d). The sample was collected from 14:40-14:59, 31 March 2018. 
(a)

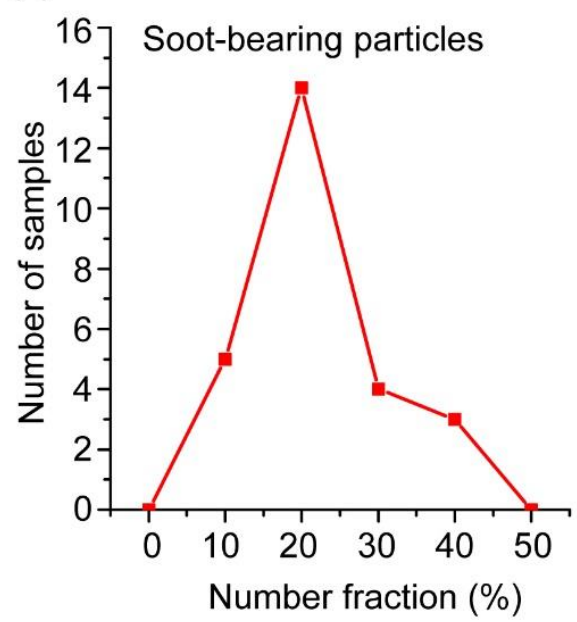

(b)

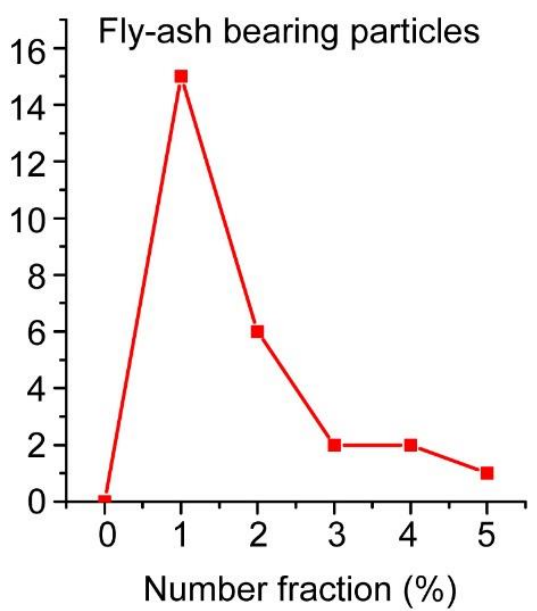

(c)

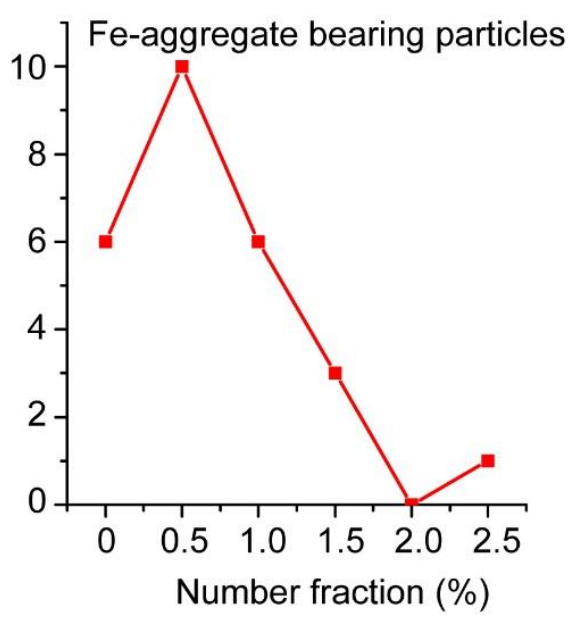

Figure S9. Histogram of the number fractions of the particles containing inclusions. (a) Soot-bearing particle number fractions. (b) Fly-ash bearing particle number fractions. (c) Fe-aggregate-bearing particle number fractions. The average values of these number fractions are $17 \%, 1.4 \%$, and $0.5 \%$, respectively. 


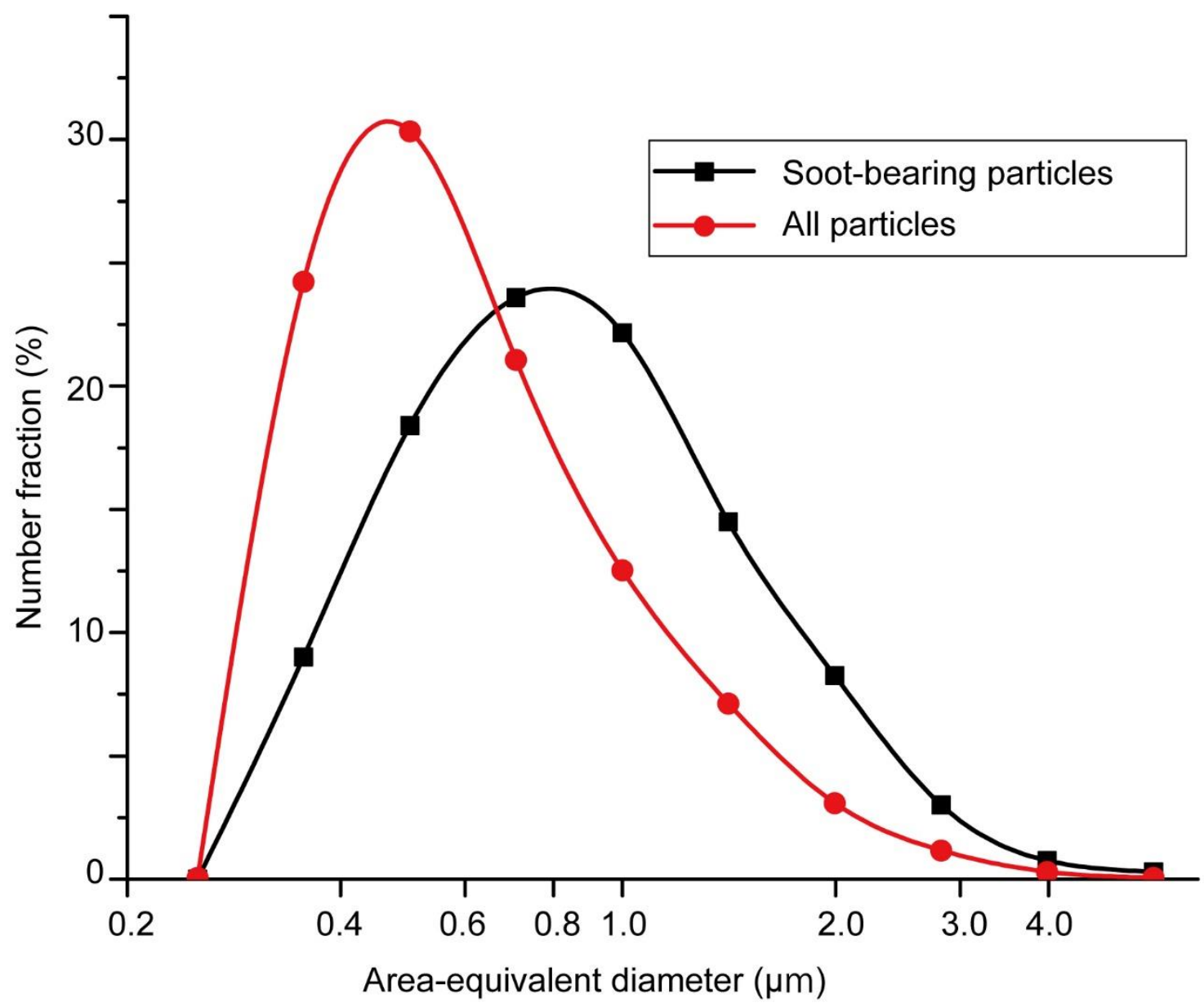

70 Figure S10. Size distributions of the soot-bearing particles (black line) and all particles (red line). The size bins are shown on a log scale $(<0.25,0.25-0.35,0.35-0.5,0.5-0.71,0.71-1.00,1.00-1.41,1.41-$ $2.00,2.00-2.82,2.82-3.98$, and $>3.98 \mu \mathrm{m})$. The sizes of the soot-bearing particles reflect those of their host particles. The numbers of all particles and soot-bearing particles are 7844 and 1331, respectively. 


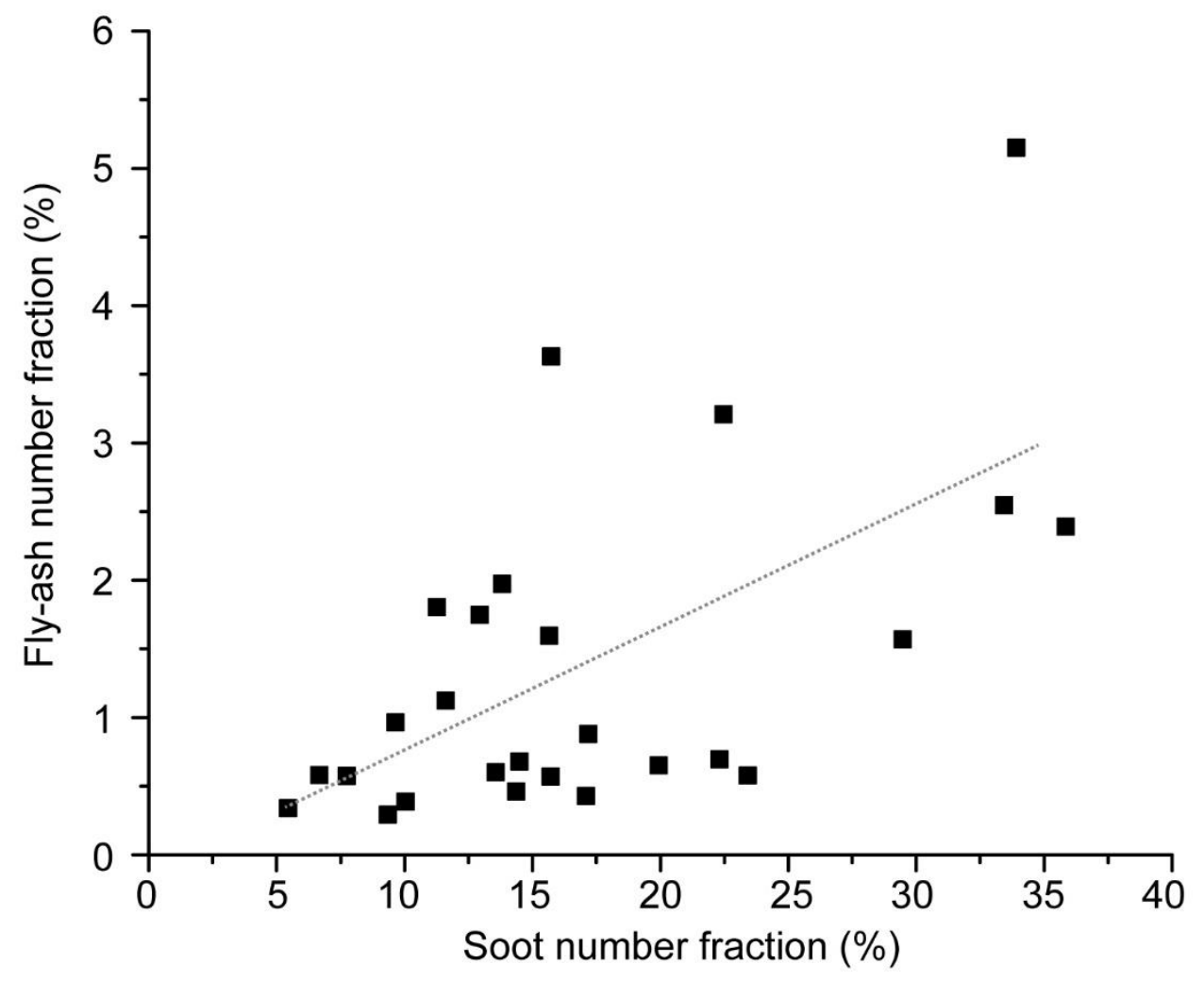

Figure S11. The relation between the number fractions of the soot and fly-ash particles within each TEM sample. $\mathrm{R}^{2}=0.35$. 
SI Table 1. Sampling date and time, number fractions of the main components and inclusions, and 80 sampling point information.

\begin{tabular}{|c|c|c|c|c|c|c|c|c|c|c|c|c|c|c|}
\hline \multicolumn{2}{|c|}{ Sampling } & \multicolumn{6}{|c|}{ Main components (Number fractions \%) } & \multicolumn{3}{|c|}{ Inclusions (\%) } & \multicolumn{3}{|c|}{ Sampling points } & \multirow[b]{2}{*}{$\begin{array}{c}\text { Biomass } \\
\text { burning } \\
\text { plume }\end{array}$} \\
\hline $\begin{array}{l}\text { Sampling } \\
\text { date }\end{array}$ & $\begin{array}{l}\text { Start } \\
\text { time } \\
\text { (UTC) }\end{array}$ & $\begin{array}{l}\text { Mineral } \\
\text { dust }\end{array}$ & Sea salt & K-bearing & Sulfate & $\begin{array}{c}\text { Carbonac } \\
\text { eous }\end{array}$ & Other & Soot & Fly ash & $\begin{array}{c}\text { Fe- } \\
\text { bearing }\end{array}$ & $\begin{array}{l}\text { Altitude } \\
(\mathrm{m})\end{array}$ & Latitude & Longitude & \\
\hline 25-Mar & $14: 00$ & 8 & 23 & 3 & 65 & 0 & 1 & 22 & 0.7 & 0.3 & 34 & 81.59619 & -16.6591 & \\
\hline 25-Mar & $15: 40$ & 9 & 9 & 4 & 75 & 0 & 3 & 14 & 2.0 & 1.3 & 541 & 81.50161 & -9.51961 & \\
\hline 25-Mar & $16: 40$ & 5 & 3 & 5 & 86 & 1 & 1 & 23 & 0.6 & 0.9 & 2797 & 81.50279 & -8.5448 & \\
\hline 26-Mar & $12: 40$ & 5 & 21 & 1 & 66 & 5 & 1 & 16 & 0.6 & 0.3 & 275 & 82.56004 & -14.1693 & \\
\hline 26-Mar & $13: 00$ & 2 & 14 & 0 & 71 & 9 & 3 & 10 & 0.4 & 0.4 & 147 & 82.50293 & -12.742 & \\
\hline 26-Mar & $15: 00$ & 1 & 6 & 6 & 70 & 12 & 5 & 14 & 0.5 & 1.4 & 5133 & 82.49932 & -14.4512 & \\
\hline 27-Mar & $14: 20$ & 4 & 14 & 3 & 62 & 12 & 5 & 17 & 0.9 & 0.4 & 271 & 82.46931 & -18.3625 & \\
\hline 27-Mar & $14: 40$ & 6 & 12 & 4 & 50 & 29 & 0 & 11 & 1.8 & 0.0 & 137 & 82.50295 & -16.564 & \\
\hline 27-Mar & $15: 40$ & 3 & 9 & 6 & 41 & 28 & 13 & 17 & 0.4 & 0.0 & 1901 & 82.50208 & -16.6887 & \\
\hline 30-Mar & $10: 00$ & 11 & 39 & 3 & 45 & 1 & 1 & 10 & 1.0 & 0.0 & 96 & 82.50611 & 6.9813 & \\
\hline 30-Mar & $10: 20$ & 7 & 31 & 2 & 45 & 15 & 0 & 9 & 0.3 & 0.3 & 71 & 82.50614 & 11.19458 & \\
\hline 30-Mar & $10: 40$ & 8 & 33 & 3 & 51 & 5 & 1 & 13 & 1.7 & 0.0 & 169 & 82.50461 & 16.70325 & \\
\hline 31-Mar & $14: 20$ & 5 & 39 & 2 & 45 & 10 & 0 & 36 & 2.4 & 1.0 & 74 & 84.04489 & -12.0732 & \\
\hline 31-Mar & $14: 40$ & 5 & 58 & 0 & 29 & 7 & 0 & 34 & 5.2 & 2.1 & 174 & 83.57378 & -14.6603 & \\
\hline 31-Mar & $15: 00$ & 5 & 33 & 3 & 43 & 16 & 0 & 33 & 2.5 & 0.3 & 73 & 83.08185 & -16.9647 & \\
\hline 2-Apr & $10: 20$ & 2 & 1 & 4 & 69 & 4 & 19 & 5 & 0.3 & 0.0 & 2883 & 81.37321 & -11.7275 & \\
\hline 2-Apr & $10: 40$ & 1 & 2 & 37 & 53 & 4 & 2 & 14 & 0.7 & 0.7 & 4930 & 81.07854 & -6.82414 & BB \\
\hline 2-Apr & 11:00 & 1 & 1 & 1 & 45 & 30 & 21 & 8 & 0.6 & 0.3 & 3459 & 80.64019 & -1.39979 & \\
\hline 3-Apr & $8: 00$ & 1 & 6 & 4 & 77 & 8 & 4 & 7 & 0.6 & 0.0 & 3475 & 81.37747 & -11.6657 & \\
\hline 3-Apr & $8: 30$ & 2 & 6 & 12 & 60 & 12 & 8 & 12 & 1.1 & 0.7 & 4279 & 80.98157 & -4.74884 & BB \\
\hline 3-Apr & 9:00 & 5 & 15 & 2 & 37 & 29 & 11 & 16 & 3.6 & 0.4 & 531 & 80.83391 & -5.49512 & \\
\hline 3-Apr & $11: 00$ & 4 & 15 & 2 & 58 & 5 & 16 & 22 & 3.2 & 0.7 & 286 & 80.91201 & -7.04061 & \\
\hline 4-Apr & $8: 00$ & 3 & 3 & 3 & 64 & 26 & 2 & 20 & 0.7 & 0.7 & 3291 & 81.37874 & -11.6985 & \\
\hline 4-Apr & $8: 30$ & 2 & 4 & 11 & 76 & 2 & 5 & 14 & 0.6 & 0.3 & 3966 & 81.07125 & -3.44506 & BB \\
\hline 4-Apr & 9:00 & 6 & 13 & 1 & 71 & 6 & 3 & 29 & 1.6 & 0.3 & 271 & 81.0339 & -2.40188 & \\
\hline Average & & 4 & 16 & 5 & 59 & 11 & 5 & 17 & 1.4 & 0.5 & & & & \\
\hline
\end{tabular}

